\title{
EFICIÊNCIA DA APLICAÇÃO DE NITROGÊNIO NO PERFILHAMENTO DO ARROZ EM TRÊS MANEJOS DE IRRIGAÇÃO
}

\author{
EFFICIENCY OF NITROGEN APPLICATION ON RICE TILLERING UNDER WATER \\ MANAGEMENT SYSTEMS
}

\author{
Ramón Felipe Méndez Larrosa ${ }^{1}$ Enio Marchezan ${ }^{2}$ Celso Aita $^{3}$ Juliano Zamberlan Coradini ${ }^{4}$
}

RESUMO

Com o objetivo de avaliar a eficiência de três modalidades de aplicação de nitrogênio (N) na cultura de arroz foi conduzido um experimento, no ano agrícola 1998/99, na Universidade Federal de Santa Maria (RS). O delineamento experimental foi bifatorial $3 \times 5 \mathrm{em}$ blocos ao acaso com parcelas subdivididas e quatro repetições. Nas parcelas principais, foram estabelecidas, no início do perfilhamento do arroz, três modalidades de aplicação da uréia: 1) Uréia + banho, na qual a uréia foi aplicada superficialmente e, no dia seguinte, deu-se um banho, inundando-se a área 14 dias depois; 2) Uréia + inundação, na qual a uréia foi aplicada um dia antes da inundação definitiva; e 3) Inundação + uréia, com a aplicação da uréia um dia após a inundação. Nas subparcelas, foram aplicadas quatro doses de $N\left(0,20,40\right.$ e $60 \mathrm{~kg} \mathrm{ha}^{-1}$ de N) e uma testemunha absoluta, sem aplicação de $N$ durante todo o ciclo da cultura. Em todos os tratamentos que receberam $N$, foram aplicados $10 \mathrm{~kg} \mathrm{ha}^{-1}$ de $\mathrm{N}$ na semeadura e $23 \mathrm{~kg} \mathrm{ha}^{-1}$ de $\mathrm{N}$ no início do alongamento de entrenós. Concluiu-se que o $N$ aplicado na etapa vegetativa até o início de alongamento de entrenós incrementa a quantidade de perfilhos e o $N$ acumulado total. Este incremento depende das modalidades de aplicação da uréia, sendo maior nos tratamentos "uréia + banho" e "uréia + inundação”, em relação à aplicação da uréia na água. $O$ incremento das doses de nitrogênio proporciona elevação na produção de grãos enquanto as modalidades de aplicação de uréia no perfilhamento não afetam a produção de grãos, utilizando-se nitrogênio na iniciação do primórdio floral.

Palavras-chave: arroz irrigado, nitrogênio, uréia.

\section{SUMMARY}

Having the objective of evaluating the efficiency of three nitrogen aplication systems in the tillering stage of rice, there was an experiment installed in the Federal University of Santa Maria (RS), Brazil, during 1998/99 growing season. The experimental design was two-factorial $3 \times 5$ in complete randomized block design with 4 replication in a split plot arrangement of treatments. Three forms of $N$ application at tillering stage were placed in the main plots: 1) $N+$ flushing where the $N$ was topdressed and a flush of water was applied one day after and then flooding fourteen days later; 2) $N$ + flooding where $N$ was topdressed the day before the definitive flooding; 3 ) flooding $+N$, with the $N$ applied in the water one day after flooding. Four rates of $N$ were applied in the plots (0,20, 40 and $60 \mathrm{Kg}$ of $\mathrm{N} \mathrm{ha}^{-1}$ ) and an absolute witness and control without $N$. In every treatment which received $N$, there was an application of $10 \mathrm{Kg} \mathrm{ha}^{-1}$ in the beginning of internode elongation. It was concluded that nitrogen application from tillering to the internode elongation increased tiller number and total $N$ uptake. This increase is dependent on the nitrogen application system being greater in treatments of $N+$ flush and $N+$ flooding in relation to the flooding $+N$ treatments. This increment of $N$ doses provides an increase in grain production, while the forms of urea application at tillering stage don't affect grain production when using $N$ in the panicle initiation.

Key words: flooded rice, nitrogen, urea.

\section{INTRODUÇÃO}

No sistema tradicional de condução da lavoura de arroz no Rio Grande do Sul, há duas etapas bem diferenciadas quanto ao regime hídrico do solo, as quais podem afetar a disponibilidade de $\mathrm{N}$ às plantas. $\mathrm{O}$ solo permanece em ambiente arejado desde o preparo até o perfilhamento quando então a lavoura é inundada, permanecendo nesta condição até período próximo a colheita.

Para melhor explorar o potencial produtivo da lavoura, o $\mathrm{N}$ é aplicado em cobertura em duas épocas: uma no perfilhamento e outra na

\footnotetext{
${ }^{1}$ Engenheiro Agrônomo, Aluno do Curso de Pós-graduação em Agronomia da Universidade Federal de Santa Maria (UFSM). Campus Universitário, 97105-900, Santa Maria, RS.

${ }^{2}$ Engenheiro Agrônomo, Doutor, Professor Titular, Departamento de Fitotecnia, Centro de Ciências Rurais (CCR), UFSM, 97105-900.

Santa Maria, RS. Pesquisador CNPq. E-mail:emarch@ccr.ufsm.br. Autor para correspondência.

${ }^{3}$ Engenheiro Agrônomo, Doutor, Professor, Departamento de Solos, UFSM. Pesquisador CNPq.

${ }^{4}$ Aluno do Curso de Agronomia da UFSM.
} 
iniciação do primórdio floral. Com isto, a primeira adubação nitrogenada de cobertura é feita no solo em condições de aerobiose, enquanto a segunda é feita em condições de alagamento. Nestas condições diferenciadas, a uréia, que é a fonte de $\mathrm{N}$ mais utilizada para o arroz irrigado, poderá apresentar perdas que comprometem sua eficiência.

Em experimentos realizados nos Estados Unidos e na Austrália, a eficiência da uréia foi maior quando aplicada em solo seco, antes de inundar, do que quando aplicada logo após a inundação (HUMPHREYS $\boldsymbol{e}$ t $\boldsymbol{a l}$. , 1987a; HEENAN \& BACON, 1989 e BOLLICH et al., 1996).

Com a aplicação da uréia em solo bem drenado e imediata inundação da área, o N deslocase no solo em profundidade seguindo o movimento da água, podendo ficar retido nos colóides, na forma de $\mathrm{N}^{-\mathrm{NH}_{4}}{ }^{+}$(HUMPHREYS et al., 1987b). Por outro lado, a uréia aplicada na água desloca-se apenas nos primeiros centímetros do solo onde é hidrolizada a $\mathrm{N}-\mathrm{NH}_{4}{ }^{+}$que se difunde tanto para a água como para o solo. Na água, poderá ocorrer perdas de $\mathrm{N}$ por volatização de $\mathrm{NH}_{3}$ enquanto que, no solo, o N-NH${ }_{4}^{+}$ pode ser nitrificado na camada oxidada. Caso o $\mathrm{N}$ $\mathrm{NO}_{3}{ }^{-}$produzido se difunda até a camada reduzida, ele poderá ser perdido por denitrificação (HUMPHREYS et al., 1987b; KATYAL \& GADALLA, 1990).

Embora a maior parte dos trabalhos indiquem que o $\mathrm{N}$ aplicado em solo drenado seja mais eficiente do que quando aplicado na água, alguns pesquisadores não encontraram diferenças na produtividade da cultura do arroz aplicando uréia nestas duas condições de solo (DEAMBROSI \& MÉNDEZ, 1995; MARIN \& SANABRIA, 1999).

Os resultados contraditórios se devem, provavelmente, às perdas diferenciadas de $\mathrm{N}$, já que elas dependem das condições de clima, solo e modalidade de aplicação de uréia. Isto evidencia a necessidade de se intensificarem os estudos relativos à eficiência da adubação nitrogenada na cultura do arroz em diferentes modalidades de aplicação do $\mathrm{N}$ e manejos de irrigação, em escala regional.

Conduziu-se este trabalho com o objetivo de determinar o manejo mais adequado da adubação nitrogenada e da irrigação para uma melhor eficiência do nitrogênio aplicado no arroz irrigado.

\section{MATERIAL E MÉTODOS}

O experimento foi conduzido na área experimental do Departamento de Fitotecnia da Universidade Federal de Santa Maria, Rio Grande do Sul, em um PLANOSSOLO HIDROMÓRFICO Eutrófico arênico pertencente à unidade de mapeamento Vacacaí (STRECK et al. 1999).
O delineamento experimental foi de blocos ao acaso com parcela subdividida e quatro repetições. Nas parcelas principais de 20 x 6m, foram estabelecidas, no início do perfilhamento (23 dias após a emergência), três formas de manejos d'água e nitrogênio (modalidades de aplicação da uréia): uréia + banho $(\mathrm{U}+\mathrm{B})$, uréia + inundação $(\mathrm{U}$ $+\mathrm{I})$ e inundação + uréia $(\mathrm{I}+\mathrm{U})$. No manejo $\mathrm{U}+\mathrm{B}$, aplicou-se a uréia superficialmente no solo drenado e, no dia seguinte, deu-se um banho, inundando-se definitivamente a área 14 dias após. No manejo U + I a área foi inundada um dia depois da aplicação de uréia e, no manejo I + U, a uréia foi aplicada na água de irrigação, um dia depois da inundação. Nas subparcelas de $6 \times 4 \mathrm{~m}$, foram aplicadas 4 doses de $\mathrm{N}$ $\left(0,20,40\right.$ e $60 \mathrm{~kg} \mathrm{ha}^{-1}$ de $\left.\mathrm{N}\right)$ e uma testemunha absoluta, sem aplicação de $\mathrm{N}$, em todo o ciclo da cultura.

A semeadura foi realizada em 21/10/98 com semeadora-adubadora de plantio direto com $0,18 \mathrm{~m}$ de espaçamento entre linhas e $180 \mathrm{~kg} \mathrm{ha}^{-1} \mathrm{de}$ sementes da variedade El Paso 144. Em todas as subparcelas, exceto na testemunha absoluta, aplicouse $10 \mathrm{~kg} \mathrm{ha}^{-1}$ de $\mathrm{N}$ na forma de uréia no dia seguinte à semeadura. No início de alongamento dos entrenós (65 dias após a emergência), após a amostragem de plantas para a determinação da concentração de $\mathrm{N}$ na matéria seca, efetuou-se uma aplicação de $23 \mathrm{~kg} \mathrm{ha}^{-1}$ de $\mathrm{N}$ em todas as parcelas exceto na testemunha absoluta.

A lâmina d'água no início dos tratamentos foi de aproximadamente $5 \mathrm{~cm}$, sendo gradativamente aumentada segundo a estatura das plantas chegando, até mais ou menos $10-15 \mathrm{~cm}$, permanecendo assim até a colheita.

No estádio de alongamento de entrenós, foi coletada a parte aérea das plantas em 3 subamostras de $0,09 \mathrm{~m}^{2}$ em cada subparcela. As subamostras foram reunidas e submetidas à secagem em estufa de circulação forçada de ar a uma temperatura de $70^{\circ} \mathrm{C}$ até massa constante. $\mathrm{O}$ tecido vegetal seco foi moído em moinho tipo Willey para a análise da concentração de $\mathrm{N}$ total, conforme a metodologia descrita por TEDESCO et al. (1995). A partir da matéria seca produzida e do teor de $\mathrm{N}$ total, foi determinado o $\mathrm{N}$ absorvido pelas plantas em cada subparcela.

Trinta dias após a emergência das plantas e oito dias depois de aplicados os tratamentos, foram coletadas cinco subamostras de solo na camada de $0-10 \mathrm{~cm}$, em cada subparcela, para a determinação dos teores de $\mathrm{N}$ mineral $\left(\mathrm{N}-\mathrm{NH}_{4}{ }^{+}\right.$e $\mathrm{N}-\mathrm{NO}_{3}{ }^{-}+\mathrm{N}-$ $\mathrm{NO}_{2}^{-}$). Após a coleta, as amostras foram mantidas em congelador a $-18^{\circ} \mathrm{C}$ até a análise. $\mathrm{O} \mathrm{N}$ mineral foi extraído do solo com uma solução salina de $\mathrm{KCl}$ e determinado em destilador de arraste de vapores, conforme descrito por TEDESCO et al. (1995). 
O perfilhamento foi avaliado através da contagem do número de colmos em um metro de linha em cada subparcela, realizando-se contagens a cada 7 dias até a estabilização do perfilhamento. Nestes locais, efetuou-se, antes do início da contagem, o desbaste de plantas para ajustar a popupação para 300 plantas $/ \mathrm{m}^{2}$.

A produção de grãos foi avaliada colhendo-se as plantas em uma área útil de $12,04 \mathrm{~m}^{2}$ de cada subparcela, quando a umidade média dos grãos estava entre 20 e $22 \%$. Após determinada a umidade fez-se a correção para $13 \%$ de umidade, objetivando estimar a produção de grãos.

Os dados referentes aos tratamentos quantitativos (doses de $\mathrm{N}$ ) foram submetidos ao teste de regressão, sendo que as médias dos tratamentos qualitativos como número de colmos por $\mathrm{m}^{2}$, amônio, nitrato, nitrito no solo nas diferentes modalidades de aplicação de uréia foram submetidas ao teste Duncan com 5\% de probabilidade de erro.

\section{RESULTADOS E DISCUSSÃO}

Para a quantidade de $\mathrm{N}$ acumulada na parte aérea do arroz, houve interação entre as modalidades de aplicação da uréia e as doses de $\mathrm{N}$. Observa-se na figura 1 , que nos tratamentos em que a aplicação de uréia foi seguida de um banho (U + B) ou da inundação imediata $(U+I)$, houve maior absorção de $\mathrm{N}$ pelas plantas, em comparação com a aplicação da uréia um dia após a inundação definitiva da área, quando se aumentou a dose de $\mathrm{N}$ aplicada no início do perfilhamento da cultura. Estes resultados concordam com os obtidos por HEENAN \& BACON (1989) no sudeste da Austrália, os quais registraram um maior aproveitamento do $\mathrm{N}$, aplicando-se a uréia um dia antes da inundação.

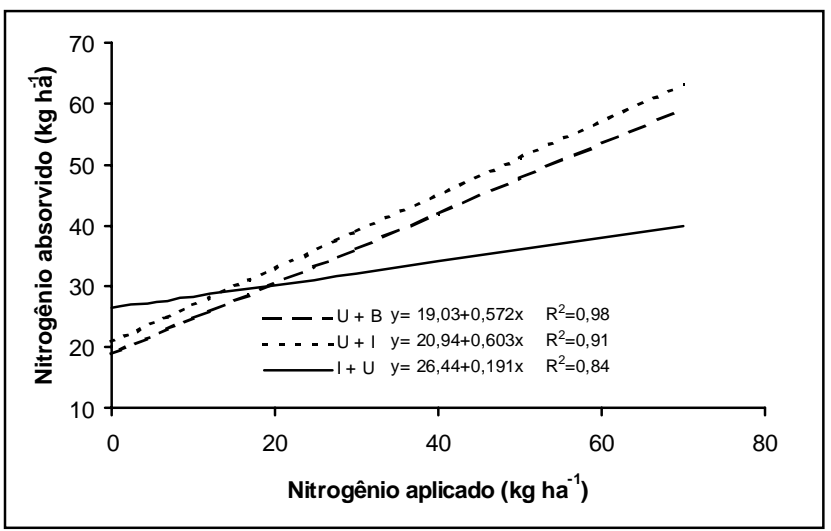

Figura 1 - Relação entre a quantidade de $\mathrm{N}$ aplicado e a quantidade de $\mathrm{N}$ absorvido pela parte aérea do arroz no início do alongamento de entrenós nos tratamentos "uréia + banho" $(\mathrm{U}+\mathrm{B})$, "uréia + inundação" (U + I) e "inundação + uréia $(I+U)$. Santa Maria, RS. 2000.
A maior quantidade de $\mathrm{N}$ absorvido pelo arroz onde a uréia foi aplicada antes da irrigação (U + B e U + I) possivelmente esteja relacionada com a maior disponibilidade de nitrogênio no solo nestes tratamentos. Observa-se na tabela 1 que o teor de $\mathrm{N}$ $\mathrm{NH}_{4}{ }^{+}$na camada de $0-10 \mathrm{~cm}$ de solo foi mais do que duas vezes superior ao tratamento em que a uréia foi aplicada sobre a lâmina de água $(\mathrm{I}+\mathrm{U})$. A aplicação de uréia em solo drenado, seguida de um banho ou da inundação, possibilita a incorporação do $\mathrm{N}$ em profundidade através da água. A uréia, assim incorporada, é hidrolizada no solo a amônio, ficando este provavelmente mais ligado aos sítios de troca dos colóides do solo e menos sujeito a perdas (HUMPHREYS et al., 1987b). Quando a uréia é aplicada diretamente na água, ela está mais sujeita a perdas por volatilização de amônio e denitrificação (HUMPHREYS et al., 1987b; KATYAL \& GADALLA, 1990).

No tratamento $\mathrm{I}+\mathrm{U}$, o solo já estava saturado com água quando da aplicação da uréia, fo que fez com que o movimento desta em profundidade fosse limitado ficando na água ou nos primeiros centímetros do solo. Hidrolizando-se na água até $\mathrm{N}-\mathrm{NH}_{4}{ }^{+}$podem ocorrer perdas de $\mathrm{N}$ por volatilização de $\mathrm{NH}_{3}$. Difundindo-se até a camada oxidada, o N-NH${ }_{4}^{+}$poderá ser transformado em nitrato e este perdido por denitrificação na camada reduzida.

Estes resultados indicam que, para áreas que demandem maiores quantidades de $\mathrm{N}$ na fase inicial da cultura, a aplicação de uréia antes da irrigação resulta em maior disponibilidade de $\mathrm{N}$ no solo e maior absorção de $\mathrm{N}$ pelas plantas.

$\mathrm{O}$ teor de amônio no solo aumentou com a dose de $\mathrm{N}$ aplicado, variando em intensidade segundo a modalidade de aplicação da uréia (Figura 2). A aplicação de uréia em solo drenado proporcionou maior quantidade de $\mathrm{N}_{-} \mathrm{NH}_{4}{ }^{+}$no solo do que a aplicação de uréia na lâmina d'água, especialmente nas maiores doses de N. Também na planta, observou-se comportamento semelhante, pois nos tratamentos com banho ( $\mathrm{U}+$ B) e inundação imediata $(U+I)$ após a aplicação de nitrogênio houve maior quantidade de $\mathrm{N}$ total acumulado em relação à aplicação de uréia na lâmina de água (Tabela 1).

Os teores de $\mathrm{N}-\mathrm{NO}_{2}{ }^{-}+\mathrm{N}-\mathrm{NO}_{3}{ }^{-}$no solo foram baixos (Tabela 1), independentemente da modalidade de aplicação do $\mathrm{N}$, confirmando resultados da literatura relativos a solos alagados (PATRICK et al., 1985), os quais mostram que estas formas de $\mathrm{N}$ são perdidas por denitrificação. Em solos de várzea, o teor de amônio é mais importante do que de nitrato já que a nitrificação 
Tabela 1 - $\mathrm{N}$ total acumulado na planta, no início do alongamento do colmo, $\mathrm{N}$ mineral do solo e colmos $\mathrm{m}^{-2}$ e produção de grão na média das doses de $\mathrm{N}$ aplicado. Santa Maria, RS. 2000.

\begin{tabular}{|c|c|c|c|c|c|}
\hline Tratamento & $\begin{array}{l}\mathrm{N} \text { total } \\
\text { acumulado } \\
\left(\mathrm{kg} \mathrm{ha}^{-1}\right)\end{array}$ & 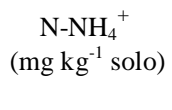 & $\begin{array}{l}\mathrm{N}^{-\mathrm{NO}_{3}}{ }^{-}+\mathrm{NO}_{2}^{-} \\
\left(\mathrm{mg} \mathrm{kg}^{-1} \text { solo) }\right.\end{array}$ & $\begin{array}{l}\text { Colmos m} \text { m }^{-2} \\
\text { 23/12/98 }\end{array}$ & $\begin{array}{l}\text { Produção } \\
\text { de grãos } \\
\mathrm{Kg} \mathrm{ha}^{-1}\end{array}$ \\
\hline $\mathrm{U}+\mathrm{B}$ & $37,55 \mathrm{a}^{(*)}$ & $8,11 \mathrm{a}$ & $1,42^{\mathrm{ns}}$ & $892 a$ & $5821^{\mathrm{ns}}$ \\
\hline $\mathrm{U}+\mathrm{I}$ & $40,25 \mathrm{a}$ & $7,80 \mathrm{a}$ & 0,58 & $801 \mathrm{ab}$ & 5634 \\
\hline $\mathrm{I}+\mathrm{U}$ & $32,55 \mathrm{~b}$ & $3,50 \mathrm{~b}$ & 0,12 & $703 \mathrm{~b}$ & 6123 \\
\hline Testemunha $^{(* *)}$ & 21,09 & 2,78 & 0,39 & 529 & 5157 \\
\hline Média & 36,72 & 6,50 & 0,70 & 799 & 5859 \\
\hline $\mathrm{CV}(\%)^{(1)}$ & 16,87 & 44,50 & 149,80 & 14,96 & 25,24 \\
\hline
\end{tabular}

1) Subparcela; ${ }^{(*)}$ Médias não seguidas por mesma letra diferem entre si pelo teste de Duncan a $5 \%$ de probabilidade de erro; ${ }^{(* *)}$ Média das parcelas sem $\mathrm{N}$ em todo o ciclo das plantas, $\mathrm{N}$ proveniente do solo, incluída na média dos tratamentos $\mathrm{U}+\mathrm{B}, \mathrm{U}+\mathrm{I}$ e I + U; ${ }^{\text {ns }}$ Teste $\mathrm{F}$ não significativo a $5 \%$ de probabilidade de erro; $\mathrm{U}+\mathrm{B}=$ Uréia $+\mathrm{Banho} ; \mathrm{U}+\mathrm{I}=$ Uréia + Inundação; I + U = Inundação + Uréia.

pode ser limitada pela dificiência de $\mathrm{O}_{2}$ ou o nitrato ser perdido por denitrificação. Assim, MÉNDEZ \& DEAMBROSI (1994) encontraram de duas a quatro vezes maior quantidade de $\mathrm{N}_{-} \mathrm{NH}_{4}{ }^{+}$do que $\mathrm{N}_{-} \mathrm{NO}_{3}{ }^{-}$ nos solos antes de serem inundados.

$\mathrm{Na}$ figura 3, são apresentados os resultados do número de colmos por $\mathrm{m}^{2}$ obtidos próximos à data de amostragem de plantas para avaliação do $\mathrm{N}$ absorvido. $\mathrm{O}$ número de colmos por área aumentou com a dose de $\mathrm{N}$, diferindo segundo a modalidade de aplicação da uréia. O aumento na dose de nitrogênio promoveu maior incremento do número de colmos por $\mathrm{m}^{2}$ nas modalidades $\mathrm{U}+\mathrm{B}$ e U+I, quando comparado com a aplicação da uréia em água. Estes resultados coincidem com aqueles relatados por HUMPHREYS et al. (1987a) na Austrália, que encontraram maior perfilhamento

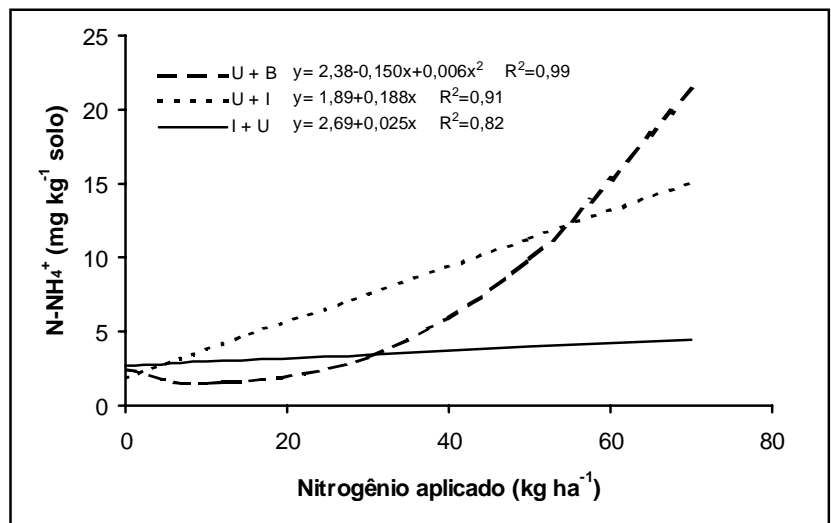

Figura 2 - Efeito da aplicação de N no conteúdo de amônio no solo, oito dias após a aplicação, nos tratamentos "uréia + banho" (U + B), "uréia + inundação" (U +I) e "inundação + uréia" (I + U). Santa Maria, RS. 2000. quando aplicaram uréia antes da inundação.

Apesar de a aplicação de uréia em solo drenado (U+B e $\mathrm{U}+\mathrm{I})$ ter proporcionado maior perfilhamento e maior absorção de $\mathrm{N}$ pelas plantas, não se observou diferenças significativas no rendimento de grãos entre as modalidades de aplicação de uréia, sendo a produção de grãos influenciada somente pelas doses de nitrogênio. (Tabela 1 e Figura 4) No intervalo estudado, não foi atingido o máximo rendimento físico de grãos. Isso indica a importância da aplicação de $\mathrm{N}$ nestes solos. Foram obtidos $12,7 \mathrm{~kg}$ de grãos por $\mathrm{kg}$ de $\mathrm{N}$ aplicado, valor inferior ao relatado por YOSHIDA (1981), de 15 - 20kg de grãos por kg de $\mathrm{N}$ aplicado. O $\mathrm{N}$ aplicado neste experimento refletiu-se no incremento da produção de grãos já que o contraste realizado entre a testemunha absoluta e os tratamentos com aplicação de $\mathrm{N}$ foi altamente significativo. A diferença entre a testemunha e a dose máxima de $\mathrm{N}$ aplicada $\left(93 \mathrm{~kg} \mathrm{ha}^{-}\right.$ ${ }^{1}$ de N) foi de $1184 \mathrm{~kg} \mathrm{ha}^{-1}$ de grãos. As condições meteorológicas foram favoráveis para a obtenção de resposta ao $\mathrm{N}$ aplicado, tendo em vista a insolação no trimestre janeiro/março Ter sido superior à normal, principalmente em janeiro (fase reprodutiva) e março (fase de maturação do arroz).

A aplicação de $\mathrm{N}$ em solo drenado, seguida de irrigação, tem proporcionado maior rendimento de grãos em trabalhos conduzidos em condições distintas de clima e de solo

(HUMPHREYS $\boldsymbol{e}$ t al., 1987a; HEENAN \& BACON, 1989; BOLLICH et al., 1996). No presente experimento, isto não foi encontrado, pois a aplicação de $\mathrm{N}\left(23 \mathrm{~kg} \mathrm{ha}^{-1}\right.$ de $\left.\mathrm{N}\right)$ em todos os tratamentos ao início do alongamento de entrenós, provavelmente supriu as deficiência de nitrogênio no tratamento de menor absorção de $\mathrm{N}$. Resultados similares ao presente experimento, em que não houve resposta de diferentes modalidades de aplicação da uréia no rendimento de grão são reportados por DEAMBROSI \& MÉNDEZ (1995) e MARIN \& SANABRIA (1999).

Os resultados apresentados demonstraram que é viável a aplicação da uréia antes de proceder a inundação, particularmente naquelas áreas com maior controle da irrigação, possibilitando a aplicação tratorizada, com redução de custos. 


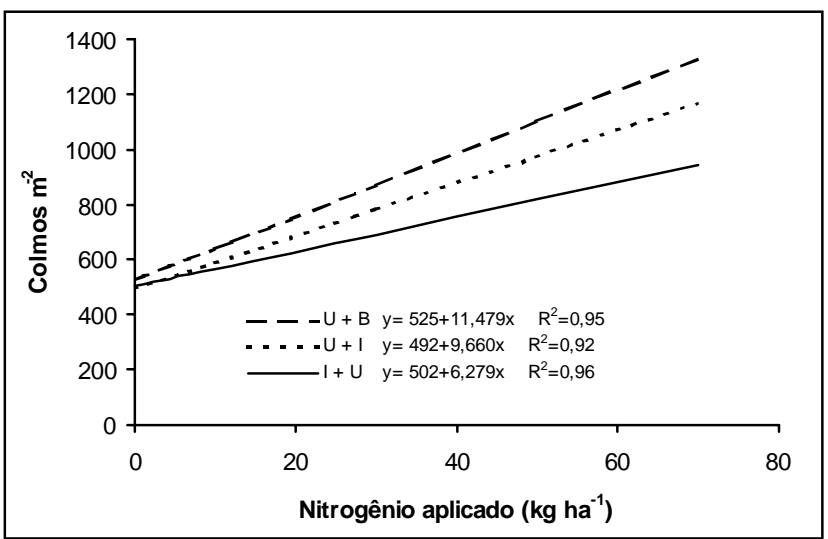

Figura 3 - Efeito do método de aplicação e da dose do $\mathrm{N}$ aplicado sobre o número de colmos. $\mathrm{m}^{-2}$ na amostragem quatro dias após o máximo perfilhamento nos tratamentos "uréia + banho" $(\mathrm{U}+\mathrm{B})$, "uréia + inundação" ( U + I) e "inundação + uréia" (I + U). Santa Maria, RS. 2000.

\section{CONCLUSÕES}

As modalidades de aplicação de $\mathrm{N}$ em solo drenado, no início do perfilhamento seguida de irrigação definitiva ou banho, proporcionam maior absorção de $\mathrm{N}$ e maior perfilhamento quando comparadas com a aplicação realizada em lâmina de água, ampliando-se estas diferenças à medida que se eleva a quantidade de $\mathrm{N}$ aplicada.

A produção de grãos aumenta com as quantidades de $\mathrm{N}$ aplicado, enquanto as modalidades de aplicação de $\mathrm{N}$ no perfilhamento não afetam a produção de grãos quando se aplica $\mathrm{N}$ na iniciação do primórdio floral.

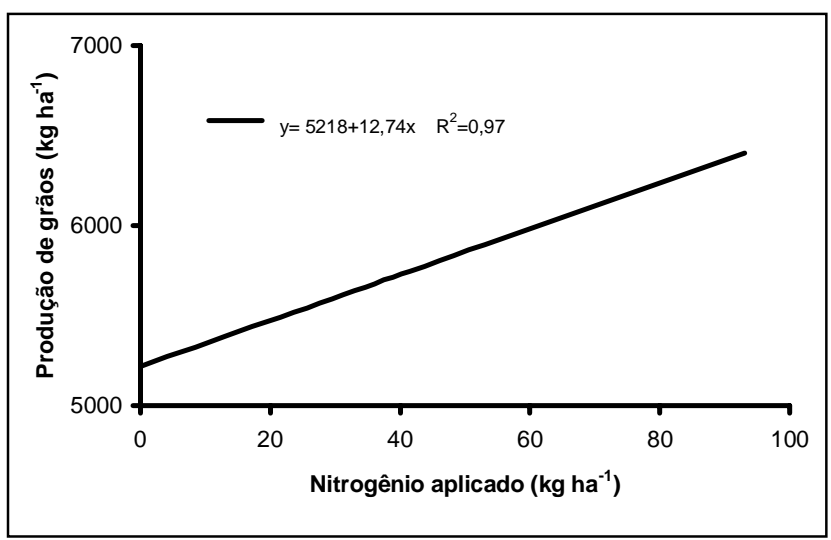

Figura 4 - Relação entre doses de N e produção de grãos. Santa Maria, RS. 2000.

\section{REFERÊNCIAS BIBLIOGRÁFICAS}

BOLLICH, P.K., GROTH, D.E., NORMAN, R., et al. Rice nutrition studies. In : ANNUAL RESEARCH REPORT, 88, 1996, Louisiana. Annais... Louisiana: Louisiana State University Agricultural Center e Louisiana Agricultural Experiment Station, 1996. 650p. p.184-211.

DEAMBROSI, E., MENDEZ, R. Eficiencia de aplicación de nitrógeno en cobertura al macollaje con respecto al riego. In: INIA Uruguay : Arroz, Resultados Experimentales 1994-1995. Treinta y Tres: INIA, 1995. Cap.2, p.2-10/213. (Serie actividades de difusión ; v.62)

HEENAN, D.P., BACON, P.E. Effects of timing and placement of urea on aerial-sown semi-dwarf rice in Southeast Australia. Aust J Agric Res, Melbourne, v.40, p.509$516,1989$.

HUMPHREYS, E., MUIRHEAD, W.A., MELHUISH, F.M., et al. Effects of time of urea application on combine-sown Calrose rice in South-east Australia. I. Crop response and N uptake. Aust J Agric Res, Melbourne, v.38, n.1, p. 101$112,1987 \mathrm{a}$.

HUMPHREYS, E., MUIRHEAD, W.A., MELHUISH, F.M., et al. Effects of time of urea application on combine-sown Calrose rice in South-east Australia. II. Mineral nitrogen transformations in the soil-water system. Aust J Agric Res, Melbourne, v.38, n.1, p.113-127, 1987b.

KATYAL, J.C., GADALLA, A.M. Fate of urea-N in floodwater. I. Relation with total N loss. Plant and Soil, Dordrecht, v.121, n.1, p.21-30, 1990.

KLAMT, E., KAMPF, N., SCHNEIDER, P. Solos de várzea no Estado do Rio Grande do Sul. Porto Alegre : Universidade Federal do Rio Grande do Sul, Faculdade de Agronomia, Departamento de Solos, 1985. 41p. (Boletim Técnico de Solos, 4).

MARIN, A.R., SANABRIA, M.C. Proyecto arroz. Campaña 1998-99. Corrientes : INTA-EEA Corrientes, 1999. Efecto de la forma de aplicación de urea sobre el rendimiento de arroz: p.117-120.

MENDEZ, R., DEAMBROSI, E. Siembra directa. In: INIA Uruguay. Arroz, resultados experimentales 1993-1994, Tomo I. Treinta y tres: INIA, 1994. Cap.3, p.3-1/3-17. (Serie actividades de difusión; v.25)

PATRICK, W.H.Jr., MIKKELSEN, D.S., WELLS, B.R.. Fertilizer technology and use. 3. ed. Madison: American Society of Agronomy, 1985. Plant nutrients behavior in flooded soils: p.197-228.

STRECK, E.V., KAMPF, N., KLAMT, E. Atualização em classificação taxonômica das unidades de mapeamento de levantamento de reconhecimento dos solos do estado do Rio Grande do Sul. Informe Emater, v.16, n.9, p. ??1999.

TEDESCO, J.M., GIANELLO, C., BISSANI, C.A., et al. Análise de solo, plantas e outros materiais. Porto Alegre: Departamento de Solos, Faculdade de Agronomia. Universidade Federal do Rio Grande do S ul, 1995. 174p.

YOSHIDA, S. Fundamentals of rice crop science. IRRI. Los Banos : IRRI, 1981. 269p.

Ciência Rural, v. 31, n. 5, 2001. 